\title{
Physician reimbursement and retention in HIV care: \\ Racial disparities in the US South
}

\author{
Zhongzhe Pan ${ }^{1}$, Bassam Dahman ${ }^{1}$, Rose S. Bono ${ }^{1}$, Lindsay M. Sabik ${ }^{2}$, Faye Z. Belgrave ${ }^{3}$, \\ Daniel E. Nixon ${ }^{4}$, April D. Kimmel ${ }^{1}$
}

${ }^{1}$ Department of Health Behavior and Policy, Virginia Commonwealth University, Richmond, Virginia, USA.

${ }^{2}$ Department of Health Policy and Management, University of Pittsburgh Graduate School of Public Health, Pittsburgh, Pennsylvania, USA.

${ }^{3}$ Department of Psychology, Virginia Commonwealth University, Richmond, Virginia, USA.

${ }^{4}$ Department of Internal Medicine, Division of Infectious Diseases, Virginia Commonwealth University, Richmond, Virginia, USA.

\section{Corresponding author}

April D. Kimmel, PhD

830 East Main Street, 4th floor, Richmond, VA 23298

Email: april.kimmel@,vcuhealth.org

Word count: 2,999

Running head: Physician reimbursement and retention in HIV care 


\begin{abstract}
Fewer than $60 \%$ of Americans diagnosed with HIV are retained in care, with racial disparities. Addressing structural barriers to care may improve outcomes along the HIV care continuum, such as retention, and promote health equity. We examined the relationship between physician reimbursement and retention in HIV care, including racial differences. Data included personlevel demographic information and administrative claims (Medicaid Analytic eXtract, 2008-12), state Medicaid-to-Medicare fee ratios (Urban Institute, 2008, 2012), and county characteristics for 15 Southern states plus District of Columbia. The fee ratio is a standardized measure of physician reimbursement capturing state variation in Medicaid relative to Medicare physician reimbursement, which is largely consistent across states. We used generalized estimating equations to assess the association between physician reimbursement ratio and retention in HIV care ( $\geq 2$ claims for physician visits, antiretroviral prescriptions, or CD4 or HIV RNA viral load tests $\geq 90$ days apart in a calendar-year). We also evaluated an increase in the fee ratio to parity, where Medicaid and Medicare physician reimbursement are equal. Stratified analysis assessed racial differences. The sample included 55,237 adult Medicaid enrollees living with HIV (179,002 enrollee-years). Enrollees were retained in HIV care for approximately three-quarters $(76.8 \%)$ of their enrollment-years, with retention lower among non-Hispanic Black (76.2\%) versus non-Hispanic White $(81.3 \%, p<0.001)$ enrollees. A 10 -percentage point increase in physician reimbursement was associated with a $4 \%$ increase in the odds of retention (aOR 1.04, 95\% CI 1.01, 1.08). In stratified analysis, increased physician reimbursement was significantly associated with retention among non-Hispanic Black but not non-Hispanic White enrollees. At parity, predicted retention was $81.1 \%(80.0 \%, 82.1 \%)$ and $80.4 \%(79 \%, 81.7 \%)$ of enrollment-years, overall and for nonHispanic Black enrollees, respectively. Higher physician reimbursement improves retention in HIV care, particularly among non-Hispanic Black individuals living with HIV, and could be a structural mechanism to promote racial equity in retention.
\end{abstract}




\section{Introduction}

Fewer than $60 \%$ of the estimated one million Americans diagnosed with HIV are retained in care, ${ }^{1}$ i.e., regular engagement with HIV-related medical care after diagnosis. Significant racial disparities exist, with non-Hispanic Blacks less likely to be retained in HIV care compared to non-Hispanic Whites. ${ }^{2}$ These differences may result in increased morbidity and mortality, ${ }^{3}$ decreased viral suppression, ${ }^{4}$ greater onward HIV transmission, ${ }^{5}$ and persistent racial inequity in access to care, quality of care, and health outcomes. ${ }^{6}$

Patient and provider interventions to increase retention in HIV care are well-studied, ${ }^{7,8}$ but less attention has focused on how changes in structural-level factors influence retention or potential disparities. Structural factors are the economic, social, political, and institutional barriers or facilitators for health care access, delivery, quality of care, and health outcomes. ${ }^{9}$ Structural inequities disproportionately impact the health of racial and ethnic groups. ${ }^{10}$

Physician reimbursement, or payment from an insurer to a clinical provider for the provision of health services, is a structural factor that may impact quality of care and health outcomes. Lower physician reimbursement is associated with worse appointment availability, ${ }^{11,}$ ${ }^{12}$ longer waiting time, ${ }^{13}$ and lower probability of receiving care. ${ }^{14}$ Physician reimbursement has not been examined for HIV care quality, including retention.

We examined the association between physician reimbursement and retention in HIV care, and whether racial differences affected this relationship. 


\section{Methods}

\section{Data}

We used the Medicaid Analytic eXtract (MAX), 2008-2012, for 15 Southern states plus District of Columbia. ${ }^{15}$ The MAX contains person-level administrative claims with information on eligibility, enrollment, demographics, outpatient visits (managed care encounters and fee-forservice), and filled prescriptions. The data comprise state-years meeting data quality and completeness metrics, which capture variability in encounter data reporting over time. ${ }^{16} \mathrm{We}$ included county-level data on HIV prevalence (AIDSVu, 2015), ${ }^{17}$ urbanicity, ${ }^{18}$ and other county characteristics reflecting socioeconomic status and health care delivery (Area Health Resource Files, 2010). ${ }^{19}$ State-level Medicaid physician reimbursement was from Medicaid-to-Medicare fee ratio indices, 2008 and $2012 .^{20}$

These data are among the best available to assess our research question. Medicaid is the largest single source of insurance for people living with HIV nationally. ${ }^{1}$ Additionally, Medicaid physician reimbursement is set at the state level, with substantial state variation ${ }^{20}$ and availability of reimbursement rates to researchers. This contrasts with other health insurers, such as Medicare (where physician reimbursement information is publicly available but rates are set centrally) and private insurers (where reimbursement data are proprietary). Further, the calendar-years used are contemporaneous due to lag times in release of Medicaid data, particularly in the more recent past as the Centers for Medicare and Medicaid Services transformed their Medicaid data collection system. Finally, the MAX have a similar demographic composition and basis of eligibility (income, disability) as current enrollees, including those living with HIV ${ }^{21}$ with approximately $70 \%$ of enrollee and enrollee-years representing states that have not experienced 
medRxiv preprint doi: https://doi.org/10.1101/2021.08.16.21262053; this version posted August 24, 2021. The copyright holder for this preprint (which was not certified by peer review) is the author/funder, who has granted medRxiv a license to display the preprint in perpetuity.

It is made available under a CC-BY-NC-ND 4.0 International license .

Medicaid expansion. ${ }^{22}$ The MAX data used in the this analysis also reflect current medical practices regarding retention in care ${ }^{23}$ and historical definitions of the outcome (see below). ${ }^{24,25}$

\section{Study population}

The study population included Medicaid enrollees aged 19-64 years identified as living with HIV, eligible for Medicaid based on income or disability, and enrolled in Medicaid within a single state over the observation period (Figure 1). We used a case identification algorithm to identify enrollees living with HIV ${ }^{26}$ To ensure complete utilization records, we excluded enrollees in a calendar-year, who were ever dually eligible for Medicare, ever enrolled in private insurance, not continuously enrolled throughout the calendar-year, $\geq 65$ years, or had missing gender or county characteristics. We did not include Tennessee enrollees, since Tennessee's Medicaid program did not have a fee-for-service component and therefore no information on physician reimbursement was available. ${ }^{20}$

\section{Key variables}

\section{Retention in HIV care}

The outcome variable was retention in HIV care $^{25}$ and measured by calendar-year, January 1-December $31 .{ }^{27}$ The baseline measure (Any Care Marker) was defined as two or more care markers within a calendar-year, $\geq 90$ days apart. Care markers included claims for routine HIV medical visits (i.e., outpatient office visit with HIV as the primary diagnosis), antiretroviral prescriptions, or HIV-related laboratory tests (e.g., CD4 count test). Care markers were identified in the claims using HIV diagnosis codes, service codes, and antiretroviral prescription drug 
medRxiv preprint doi: https://doi.org/10.1101/2021.08.16.21262053; this version posted August 24, 2021. The copyright holder for this preprint (which was not certified by peer review) is the author/funder, who has granted medRxiv a license to display the preprint in perpetuity.

It is made available under a CC-BY-NC-ND 4.0 International license .

codes. In the current study, $76.8 \%$ of total enrollee-years were retained in HIV care, slightly exceeding recent estimates. $^{27}$

\section{State-level physician reimbursement}

Medicaid physician reimbursement was measured using the primary care Medicaid-toMedicare fee ratio. This ratio compares physician reimbursement in the fee-for-service component of Medicaid with Medicare reimbursement for the same primary care services, by state. ${ }^{20}$ The ratios create a state-level index of relative Medicaid reimbursement levels, since Medicare physician reimbursement is typically higher than Medicaid physician reimbursement and intended to reflect costs of care, with limited geographic variation across states. ${ }^{28}$ Use of the Medicaid-to-Medicare fee ratio as a proxy for Medicaid physician reimbursement is consistent with the literature. ${ }^{26,29}$ Medicaid-to-Medicare fee ratios were available for 2008 and 2012; we assumed a linear trend, applying estimated fee ratios for 2009, 2010, and 2011. ${ }^{30}$

\section{Control variables}

At the individual level, we included age at last observation in the observation period (grouped in 10-year intervals), gender, and race and ethnicity. ${ }^{31}$ We controlled for enrollee health status, including presence of co-infections (hepatitis B and/or C), non-AIDS comorbidities using the Charlson Comorbidity Index,${ }^{32}$ and AIDS-defining illness. ${ }^{33}$ We also controlled for enrollee urbanicity, where counties in a federally designated metropolitan statistical area of $\geq 50,000$

population were classified as urban and those in nonmetropolitan areas as rural. ${ }^{18}$ Additionally, we controlled for managed care enrollment, defined as enrollment $\geq 6$ months in a calendaryear. $^{34}$ 
At the county-level, we controlled for HIV prevalence, as well as physician availability and the number of hospital beds for non-specialized short-term care, which together were a proxy for availability of HIV clinical care. ${ }^{35}$ We additionally controlled for residential countylevel socioeconomic status, including percent of the population with less than a high school diploma, percent currently unemployed, and median household income. ${ }^{36}$

\section{Statistical analysis}

Our study is a based on longitudinal data where Medicaid enrollees were observed over years. We described sample characteristics overall and by race, testing racial differences using chi-squared tests for categorical variables and t-tests for continuous variables. When examining the relationship between physician reimbursement and retention in HIV care, we used generalized estimating equations considering potential within-person correlation of outcomes

over multiple calendar-years of an individual's Medicaid enrollment. ${ }^{37,38}$ We specified a logit link, binomial distribution; the independent correlation matrix was found as the best fit model using the quasi information criterion. Given racial disparities in retention in HIV care, ${ }^{39}$ we performed stratified analysis for non-Hispanic White and non-Hispanic Black enrollees; we did not conduct analysis by Hispanic ethnicity due to small sample size and limited variation in the key variable of interest within this sub-sample. All models included state fixed effects to control for unobserved time-invariant heterogeneity in demographic or healthcare system characteristics across states, and year fixed effects to control for trends in retention in HIV care over time.

\section{Additional analysis}


We applied alternative definitions of retention in care. We restricted care markers to CD4 cell count or HIV RNA viral load tests only (Lab Tests $),{ }^{1}$ as well as routine HIV medical care visits only (Routine Visits). ${ }^{25}$ Additionally, we considered an extended observation period of 15 months (i.e., January 1 of a given year through March 31 of the subsequent year) to account for real-world delays in medical visits and other services; here, we restricted the sample to those continuously enrolled in Medicaid for at least two years.

We considered separate sub-populations. We restricted the sample to enrollees living with HIV and requiring more intensive HIV management (Intensive Management). This subsample included enrollees who were pregnant, had HIV-related nephropathy, had an AIDSdefining illness, or received sulfamethoxazole/trimethoprim for pneumocystis jiroveci pneumonia treatment within a calendar-year. ${ }^{40} \mathrm{We}$ also evaluated the relationship between physician reimbursement and retention in HIV care separately by enrollee payment type (i.e., fee-for-service versus managed care). This examined potential estimation biases associated with different service utilization patterns in the managed care versus fee-for-service components of Medicaid.

We also applied an alternative physician reimbursement index — the Medicaid-toMedicare fee ratio for all services. This captured potential differences in practice patterns among specialist providers, including HIV clinicians. Finally, we examined the relationship at parityi.e., a physician fee ratio of 1 , indicating Medicaid and Medicare physician reimbursement are equal. We predicted the percentage retained in HIV care and change in the probability of retention, overall and by race, and holding covariates constant at their mean values.

Analyses were conducted in SAS version 9.4 and used two-sided tests with a significance threshold of $p<0.05$. 


\section{Results}

\section{Descriptive statistics}

The sample included 55,273 enrollees living with HIV and 179,002 enrollee-years (Table 1). Enrollees were retained in care for over three-quarters of their total enrollment-years, with non-Hispanic White retained more than non-Hispanic Black enrollees $(p<0.001)$. Compared to non-Hispanic Black enrollees, non-Hispanic White enrollees were older, more likely to be male, and had more co-infections, comorbidities, and AIDS-defining illnesses $(p<0.01)$.

\section{Main analysis}

We found a positive and significant relationship between physician reimbursement and retention in HIV care (Table 2). A 10-percentage point increase in the Medicaid-to-Medicare fee ratio was associated with a $4 \%$ increase in the likelihood of retention in care (adjusted odds ratio $1.04 ; 95 \%$ confidence interval $1.01,1.08)$. In stratified analysis, there was an association only among non-Hispanic Black enrollees (1.08; 1.05, 1.12).

\section{Additional analysis}

Baseline findings were robust to alternative definitions of retention in care and the physician reimbursement index (Figure 2). When using the Lab Tests definition of retention, a 10 -percentage point increase in the fee ratio was associated with a $21 \%$ increase $(1.18,1.24)$ in the adjusted odds of retention in care. Similarly, when using the Routine Visits definition of retention, a 10-percentage point increase in the fee ratio was associated with a $10 \%$ increase $(1.07,1.13)$ in the adjusted odds of retention in care. The relationship remained significant when extending the observation period for retention to 15 months. In stratified analysis, the 
medRxiv preprint doi: https://doi.org/10.1101/2021.08.16.21262053; this version posted August 24, 2021. The copyright holder for this preprint (which was not certified by peer review) is the author/funder, who has granted medRxiv a license to display the preprint in perpetuity.

It is made available under a CC-BY-NC-ND 4.0 International license .

relationship was statistically significant among non-Hispanic Black enrollees, regardless of definition of retention in HIV care; similar to the stratified analysis in the main analysis, there was no statistically significant relationship among non-Hispanic White enrollees. When using the fee ratio for all services, versus primary care services only, the relationship for the full sample and stratified analysis was similar to the baseline findings.

Findings were mixed when examining the relationship in different sub-populations. In the Intensive Management sample, we found no significant relationship between physician reimbursement and retention in care. However, for both the Medicaid fee-for-service and the Medicaid managed care sub-populations, a 10-percentage point increase in the fee ratio was positively and significantly associated with retention in care. In stratified analysis, findings were similar for non-Hispanic Black enrollees. We found no significant relationship among nonHispanic White enrollees across all sensitivity analyses, with the exception of fee-for-service enrollees.

When predicting an increase to parity, retention in HIV care increased overall by $2.7 \%$ $(0.6 \%, 4.7 \%)$ compared to the main analysis, with enrollees retained in care for $81.1 \%$ of enrollment-years. For non-Hispanic Black enrollees, retention increased by $5.4 \%(2.4 \%, 8.3 \%)$, with $80.4 \%$ of their enrollee-years retained in HIV care. Results were not significant for nonHispanic White enrollees.

\section{Discussion}

Retention in HIV care, and racial disparities in retention, remain ongoing US challenges that could be mitigated by addressing structural barriers to care. This study finds that retention in HIV care is higher among enrollees living in states with higher Medicaid physician 
reimbursement, regardless of different definitions of care retention, enrollee payment type, and type of fee ratio. Notably, in stratified analyses, this relationship occurs only among nonHispanic Black Medicaid enrollees.

Our findings suggest that even modest increases in physician reimbursement may improve retention in HIV care. More sizeable increases have been implemented, but only in the relative short-term. For example, the Affordable Care Act increased state-level Medicaid physician reimbursement for primary care services on average $73 \%$ nationally during $2013-14$ to promote primary care physician participation in Medicaid. ${ }^{20}$ Recently, 37 states have temporarily increased Medicaid provider reimbursement for certain providers in response to the COVID-19 public health emergency. ${ }^{22,41}$ These temporary increases suggest that states recognize the importance of Medicaid reimbursement in supporting access to care, but may face constraints that preclude committing to substantial payment changes over the longer term. We consider a more modest 10-percentage point increase in state-level Medicaid physician reimbursementwhich may be economically feasible for some state Medicaid programs. This increase was associated with a $4 \%-39 \%$ increase in the odds of retention in HIV care, with potential downstream improvements: increased retention in HIV care may improve HIV RNA viral suppression, ${ }^{4}$ thereby reducing morbidity, mortality, ${ }^{3}$ and HIV transmission. ${ }^{5,42}$

Increasing physician reimbursement may reduce racial disparities in retention in HIV care and improve health equity. Increased physician reimbursement was associated with higher retention among non-Hispanic Black — but not non-Hispanic White-enrollees in stratified analyses. One explanation for racial differences in the association is the manifold structural disparities inherently faced by Blacks. Reduction in one structural barrier might have a disproportionately more favorable impact for non-Hispanic Black than non-Hispanic White 
individuals living with HIV, who face fewer structural barriers. The removal of one structural barrier is likely to have greater weight for groups burdened by many structural barriers; that is, our results may reflect a ceiling effect among non-Hispanic White enrollees, who had a higher proportion of their enrollment retained in care (81\%) than non-Hispanic Black enrollees (76\%). Indeed, increasing Medicaid physician reimbursement to parity may be a mechanism to narrow the gap between non-Hispanic Whites and non-Hispanic Blacks retained in HIV care.

Another explanation is that the providers in practices with larger shares of racial and ethnic minority patients may benefit more from increased physician reimbursement. Evidence suggests that practices with higher shares of racial and ethnic minority patients $(>70 \%)$ are more likely to have patients participating in Medicaid, be located in states with lower Medicaid-toMedicare fee ratios, and be located in communities with lower private insurance reimbursement. ${ }^{43}$ Providers in these practices have reported care challenges-including shorter visit length, delays in reporting from other providers, and a higher scope of care without specialty referrals - that influence quality of care, care coordination, and possibly care retention. ${ }^{43}$ Other research indicates that clinics serving at least $30 \%$ racial and ethnic minority patients have medically and psychosocially more complex patients, lower access to medical supplies and referral specialists, fewer exam rooms per physician, and a more chaotic work environment, with physicians reporting lower control of their work and job satisfaction. ${ }^{44}$ Lower physician reimbursement may therefore function as an unseen structural barrier to racial equity in health care. ${ }^{45}$

This study is the first to examine the relationship between physician reimbursement and HIV care quality, building on the broader literature on physician reimbursement as a potential system-level barrier to high quality care. This study’s findings among non-Hispanic Black 
medRxiv preprint doi: https://doi.org/10.1101/2021.08.16.21262053; this version posted August 24, 2021. The copyright holder for this preprint (which was not certified by peer review) is the author/funder, who has granted medRxiv a license to display the preprint in perpetuity.

It is made available under a CC-BY-NC-ND 4.0 International license .

Medicaid enrollees living with HIV align with previous work indicating that higher physician reimbursement is associated with more frequent physician visits, ${ }^{14,29}$ increased usual source of care, ${ }^{29}$ and outpatient department visits. ${ }^{14,29}$ Study findings also parallel the limited research on physician reimbursement for HIV care: over half of general internists reported that higher physician reimbursement for one clinical service (counseling time) would facilitate routine HIV screening, ${ }^{46}$ a key element of the HIV care continuum. Finally, our work is among the first to examine the differential impact of physician reimbursement on quality of care by race.

Disentangling how upstream factors shape disparities in quality of care is critical to undermining structural racism and ending racial disparities in health and healthcare.

\section{Limitations}

First, the fee ratio reflects physician reimbursement for Medicaid fee-for-service versus Medicaid managed care. However, physician reimbursement for managed care approximates feefor-service reimbursement. ${ }^{47}$ Second, we conducted the analysis using the Medicaid-to-Medicare fee ratio for primary care services, which does not fully align with the care markers used to define retention in HIV care. This index also may not capture changes in utilization of specialist services, particularly among non-Hispanic White enrollees with HIV who are more likely to see infectious disease specialists for their usual care. ${ }^{48}$ However, our findings were robust when examining the Medicaid-to-Medicare fee ratio for all services, which captures specialist practice patterns. Third, our measure of physician reimbursement cannot capture payments clinicians may receive from the federal Ryan White HIV/AIDS Program for services provided to Medicaid enrollees but not reimbursed by Medicaid, although this is unlikely in our sample. 
Fourth, a calendar-year definition of retention in care may underestimate enrollee retention. ${ }^{25}$ Administrative claims, versus outcomes from clinical trials or cohort studies, provide a real-world snapshot of health system interactions, including variation in appointment availability and delays in obtaining care. We account for this reality when extending the observation period for retention in HIV care from 12 to 15 months, with similar findings. Fifth, we could not control for variation in provider- or clinic-level characteristics, as claims data do not allow precise identification of an enrollee's primary provider of record (including primary HIV provider). We also could not control for all relevant social and behavioral barriers to retention in care, ${ }^{49}$ since the data do not include information on individual social determinants of health (e.g., housing insecurity). Moreover, limitations in Medicaid coverage for substance use or mental health care prior to ACA implementation coupled with wide state-level variation in such coverage precluded accurate identification of substance use and behavioral health disorders. ${ }^{50,51}$ Finally, we conducted the analysis based on a single geographic region, the US South. Since physician reimbursement in most Southern states is higher than the national average (see Supplement), ${ }^{20}$ we anticipate that our findings would generalize beyond the South.

\section{Conclusions}

Increasing physician reimbursement may be a feasible policy solution to improve, and promote racial equity in, quality of care for people living with HIV. Addressing structural barriers such as low physician reimbursement may improve retention in HIV care among nonHispanic Black individuals living with HIV, improve racial equity in retention, and facilitate achievement of national goals to improve health outcomes in this population. 


\section{Acknowledgements}

This work was supported in part by the National Institutes of Health (award number R01 MD11277) and the Blick Scholars Program at Virginia Commonwealth University. The funders did not contribute to the design and conduct of the study; collection, management, analysis, and interpretation of the data; preparation, review, or approval of the manuscript; and decision to submit the manuscript for publication. There are no known conflicts of interest, financial or otherwise. This work was previously presented in part at the AcademyHealth Annual Research Meeting (abstract number 439, July 28-August 6, 2020, Virtual meeting). 
medRxiv preprint doi: https://doi.org/10.1101/2021.08.16.21262053; this version posted August 24, 2021. The copyright holder for this preprint (which was not certified by peer review) is the author/funder, who has granted medRxiv a license to display the preprint in perpetuity.

It is made available under a CC-BY-NC-ND 4.0 International license .

\section{References}

1. Centers for Disease Control and Prevention. Understanding the HIV Care Continuum. Accessed March 24th, 2020. https://www.cdc.gov/hiv/pdf/library/factsheets/cdc-hiv-carecontinuum.pdf

2. Anderson AN, Higgins CM, Haardörfer R, Holstad MM, Nguyen MLT, Waldrop-Valverde D. Disparities in retention in care among adults living with HIV/AIDS: A systematic review. AIDS Behav. 2019:1-13.

3. Mugavero MJ, Westfall AO, Cole SR, et al. Beyond core indicators of retention in HIV care: missed clinic visits are independently associated with all-cause mortality. Clin Infect Dis. 2014;59(10):1471-1479.

4. Mugavero MJ, Amico KR, Westfall AO, et al. Early retention in HIV care and viral load suppression: implications for a test and treat approach to HIV prevention. J Acquir Immune Defic Syndr. 2012;59(1):86.

5. Cohen MS, Chen YQ, McCauley M, et al. Antiretroviral therapy for the prevention of HIV1 transmission. N Engl J Med. 2016;375(9):830-839.

6. Crepaz N, Dong X, Wang X, Hernandez AL, Hall HI. Racial and ethnic disparities in sustained viral suppression and transmission risk potential among persons receiving HIV care-United States, 2014. MMWR Morb Mortal Wkly Rep. 2018;67(4):113.

7. Higa DH, Marks G, Crepaz N, Liau A, Lyles CM. Interventions to improve retention in HIV primary care: a systematic review of US studies. Curr HIV/AIDS Rep. 2012;9(4):313325.

8. Higa DH, Crepaz N, Mullins MM. Identifying best practices for increasing linkage to, retention, and re-engagement in HIV medical care: findings from a systematic review, 1996-2014. AIDS Behav. 2016;20(5):951-966.

9. Sumartojo E. Structural factors in HIV prevention: concepts, examples, and implications for research. AIDS. 2000;14:S3-S10.

10. Baciu A, Negussie Y, Geller A, Weinstein JN, National Academies of Sciences E, Medicine. The root causes of health inequity. Communities in Action: Pathways to Health Equity. National Academies Press (US); 2017. Accessed August 12th. https://www.ncbi.nlm.nih.gov/books/NBK425845/

11. Polsky D, Richards M, Basseyn S, et al. Appointment availability after increases in Medicaid payments for primary care. N Engl J Med. 2015;372(6):537-545.

12. Candon M, Zuckerman S, Wissoker D, et al. Declining Medicaid fees and primary care appointment availability for new Medicaid patients. JAMA Intern Med. 2018;178(1):145146.

13. Sharma R, Tinkler S, Mitra A, Pal S, Susu-Mago R, Stano M. State Medicaid fees and access to primary care physicians. Health Econ. 2018;27(3):629-636.

14. Decker SL. Changes in Medicaid physician fees and patterns of ambulatory care. Inquiry. 2009;46(3):291-304.

15. Census Bureau. Census Regions and Divisions of the United States. Accessed March 23rd, 2020. https://www2.census.gov/geo/pdfs/maps-data/maps/reference/us regdiv.pdf

16. Byrd V, Dodd A. Assessing the usability of encounter data for enrollees in comprehensive managed care MAX, 2007-2009. 2012. Medicaid Policy Brief. Accessed August 12th, 2021. https://www.cms.gov/Research-Statistics-Data-and-Systems/Computer-Data-andSystems/MedicaidDataSourcesGenInfo/Downloads/MAX IB 15 AssessingUsability.pdf 
medRxiv preprint doi: https://doi.org/10.1101/2021.08.16.21262053; this version posted August 24, 2021. The copyright holder for this preprint (which was not certified by peer review) is the author/funder, who has granted medRxiv a license to display the preprint in perpetuity.

It is made available under a CC-BY-NC-ND 4.0 International license .

17. Emory University RSoPH. AIDSVu. Accessed March 23, 2020.

https://aidsvu.org/resources/\#/datasets

18. Ingram DD, Franco SJ. 2013 NCHS urban-rural classification scheme for counties. Vol. 2. 2014. Accessed August 12th. https://www.cdc.gov/nchs/data/series/sr 02/sr02 166.pdf

19. Department of Health and Human Services. Area health resources files Accessed March 23rd, 2020. https://data.hrsa.gov/data/download

20. Zuckerman S. How much will Medicaid physician fees for primary care rise in 2013? Evidence from a 2012 survey of Medicaid physician fees. Vol. 2021. 2012. https://www.kff.org/wp-content/uploads/2013/01/8398.pdf

21. Foundation KF. Medicaid and HIV: A national analysis. 2011. September 2. Accessed August 12th, 2021. https://www.kff.org/wp-content/uploads/2013/01/8218.pdf

22. Kaiser Family Foundation. Medicaid emergency authority tracker: Approved state actions to address COVID-19. Accessed Feb 13th, 2021. https://www.kff.org/medicaid/issuebrief/medicaid-emergency-authority-tracker-approved-state-actions-to-address-covid-19/

23. Craw JA, Bradley H, Gremel G, et al. Retention in care services reported by HIV care providers in the United States, 2013 to 2014. J Int Assoc Provid AIDS Care. 2017;16(5):460-466.

24. Health Resources \& Services Administration. Core performance measures. Accessed September 30th, 2018. https://hab.hrsa.gov/sites/default/files/hab/clinical-qualitymanagement/coremeasures.pdf

25. Health Resources \& Services Administration. HAB HIV Core Clinical Performance Measures for

Adult/Adolescent Clients: Group 1 Accessed March 24th, 2020. https://hab.hrsa.gov/sites/default/files/hab/clinical-qualitymanagement/archivedadolescentadult.pdf

26. Bono RS, Dahman B, Sabik LM, et al. Human Immunodeficiency Virus-Experienced Clinician Workforce Capacity: Urban-Rural Disparities in the Southern United States. Clin Infect Dis. 2021;72(9):1615-1622.

27. Priest JL, Irwin DE, Evans KA, Oglesby AK, Brady BL. Benchmarking HIV quality measures across US payer types. Popul Health Manag. 2020;23(2):146-156.

28. Hahn Y. The effect of Medicaid physician fees on take-up of public health insurance among children in poverty. $J$ Health Econ. 2013;32(2):452-462.

29. Callison K, Nguyen BT. The effect of medicaid physician fee increases on health care access, utilization, and expenditures. Health Serv Res. 2018;53(2):690-710.

30. Maclean JC, McClellan C, Pesko MF, Polsky D. Reimbursement rates for primary care services: Evidence of spillover effects to behavioral health. Accessed August 12th, 2021. https://www.nber.org/papers/w24805

31. Althoff KN, Rebeiro P, Brooks JT, et al. Disparities in the quality of HIV care when using US Department of Health and Human Services indicators. Clin Infect Dis. 2014;58(8):1185-1189.

32. Charlson ME, Pompei P, Ales KL, MacKenzie CR. A new method of classifying prognostic comorbidity in longitudinal studies: development and validation. J Chronic Dis. 1987;40(5):373-383.

33. Schneider E, Whitmore S, Glynn MK, Dominguez KL, Mitsch A, McKenna MT. Revised surveillance case definitions for HIV infection among adults, adolescents, and children 
medRxiv preprint doi: https://doi.org/10.1101/2021.08.16.21262053; this version posted August 24, 2021. The copyright holder for this preprint (which was not certified by peer review) is the author/funder, who has granted medRxiv a license to display the preprint in perpetuity. It is made available under a CC-BY-NC-ND 4.0 International license .

aged $<18$ months and for HIV infection and aids among children aged 18 months to $<13$ years---United States, 2008. MMWR Morb Mortal Wkly Rep. 2008;57(10):1-12.

34. Franco Montoya D, Chehal PK, Adams EK. Medicaid Managed Care's Effects on Costs, Access, and Quality: An Update. Annu Rev Public Health. 2020;41:537-549.

35. Terzian A, Younes N, Greenberg AE, et al. Identifying spatial variation along the HIV care continuum: the role of distance to care on retention and viral suppression. AIDS Behav. 2018;22(9):3009-3023.

36. Rebeiro PF, Howe CJ, Rogers WB, et al. The relationship between adverse neighborhood socioeconomic context and HIV continuum of care outcomes in a diverse HIV clinic cohort in the Southern United States. AIDS Care. 2018:1-9.

37. Zeger SL, Liang K-Y. Longitudinal data analysis for discrete and continuous outcomes. Biometrics. 1986:121-130.

38. Liang K-Y, Zeger SL. Longitudinal data analysis using generalized linear models. Biometrika. 1986;73(1):13-22.

39. Dasgupta S. Disparities in consistent retention in HIV care-11 states and the District of Columbia, 2011-2013. MMWR Morb Mortal Wkly Rep. 2016;65

40. Department of Health and Human Services. Guidelines for the Use of Antiretroviral Agents in Adults and Adolescents Living with HIV. Vol. 2020. 2009.

https://clinicalinfo.hiv.gov/en/guidelines-archive

41. Schubel J. States are leveraging Medicaid to respond to COVID-19. Accessed February 13th, 2021. https://www.cbpp.org/research/health/states-are-leveraging-medicaid-torespond-to-covid-19

42. Cohen MS, Chen YQ, McCauley M, et al. Prevention of HIV-1 infection with early antiretroviral therapy. N Engl J Med. 2011;365(6):493-505.

43. Reschovsky JD, O'Malley AS. Do primary care physicians treating minority patients report problems delivering high-quality care? Practice resources appear to be a determining factor in whether or not physicians treating predominantly minority patients deliver care of adequate quality. Health Aff (Millwood). 2008;27(Supp11):w222-w231.

44. Varkey AB, Manwell LB, Williams ES, et al. Separate and unequal: clinics where minority and nonminority patients receive primary care. Arch Intern Med. 2009;169(3):243-250.

45. Bailey ZD, Krieger N, Agénor M, Graves J, Linos N, Bassett MT. Structural racism and health inequities in the USA: evidence and interventions. The Lancet. 2017;389(10077):1453-1463.

46. Korthuis PT, Berkenblit GV, Sullivan LE, et al. General internists' beliefs, behaviors, and perceived barriers to routine HIV screening in primary care. AIDS Educ Prev. 2011;23(3_supplement):70-83.

47. Yocom C. Medicaid payment: Comparisons of selected services under fee-for-service, managed care, and private insurance. 2014. Accessed August 12th, 2021. https://www.gao.gov/products/gao-14-533

48. Heslin KC, Andersen RM, Ettner SL, Cunningham WE. Racial and ethnic disparities in access to physicians with HIV-related expertise: findings from a nationally representative study. J Gen Intern Med. 2005;20(3):283-289.

49. Yehia BR, Stewart L, Momplaisir F, et al. Barriers and facilitators to patient retention in HIV care. BMC Infect Dis. 2015;15(1):1-10. 
medRxiv preprint doi: https://doi.org/10.1101/2021.08.16.21262053; this version posted August 24, 2021. The copyright holder for this preprint (which was not certified by peer review) is the author/funder, who has granted medRxiv a license to display the preprint in perpetuity. It is made available under a CC-BY-NC-ND 4.0 International license.

50. Andrews CM, Grogan CM, Smith BT, et al. Medicaid benefits for addiction treatment expanded after implementation of the Affordable Care Act. Health Aff (Millwood). 2018;37(8):1216-1222.

51. Grogan CM, Andrews C, Abraham A, et al. Survey highlights differences in Medicaid coverage for substance use treatment and opioid use disorder medications. Health Aff (Millwood). 2016;35(12):2289-2296. 
Figure 1. Sample selection process

$$
\begin{aligned}
& \text { Medicaid enrollees living with HIV in } \\
& 15 \text { Southern states and DC } \\
& (\mathrm{Ny}=386,890)
\end{aligned}
$$

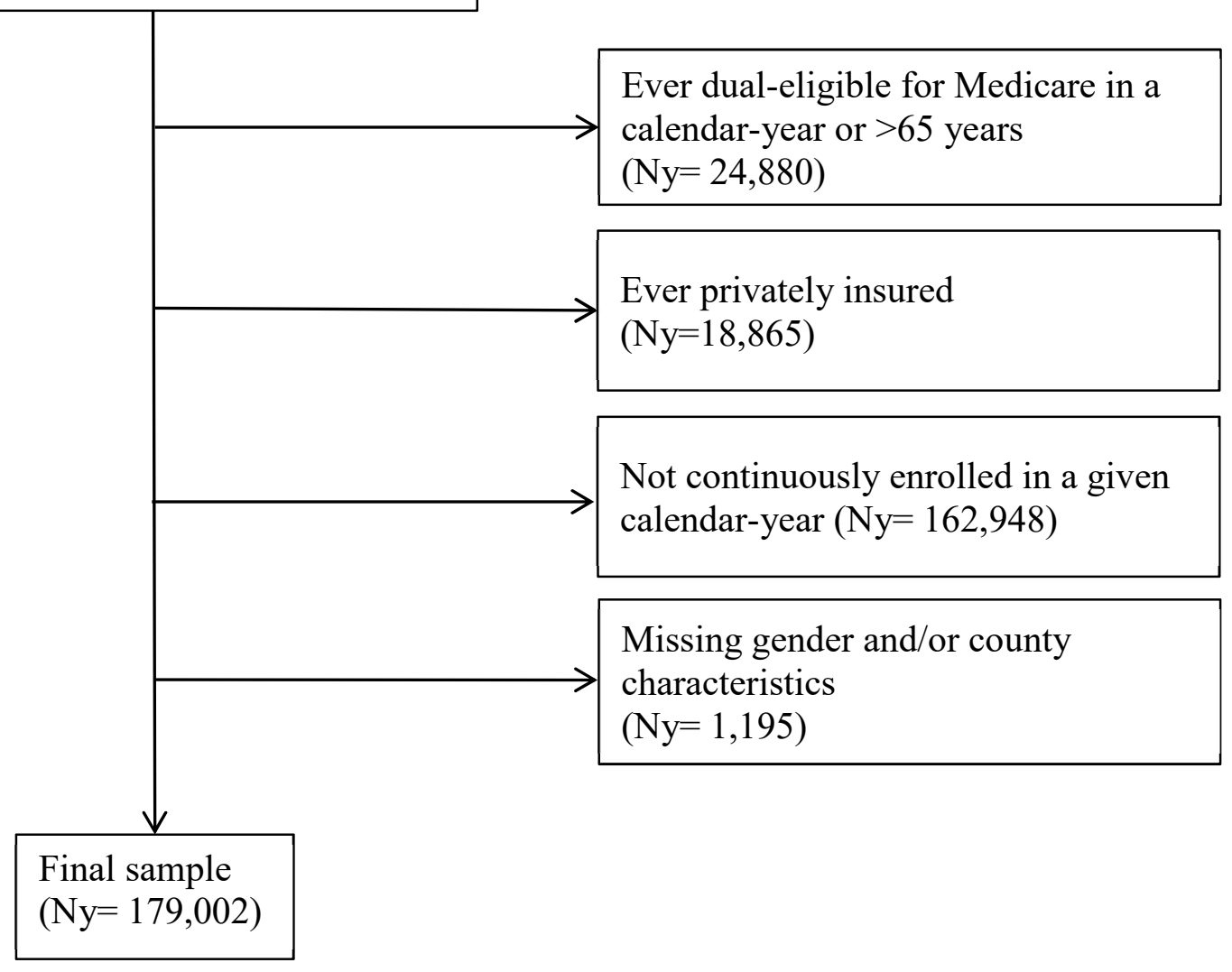

Legend: Medicaid enrollees living with HIV in 15 Southern states (Alabama, Arkansas, Delaware, Florida, Georgia, Kentucky, Lousiana, Maryland, Mississippi, North Carolina, Oklahoma, South Carolina, Texas, Virginia, West Virginia) and the District of Columbia were identified using an HIV identification algorithm. ${ }^{26}$ Enrollees were excluded from the sample if they were ever dually eligible for Medicare, older than 65 years, or ever privately insured, or with missing gender and/or county characteristics. 
Figure 2. State-level Medicaid physician reimbursement and retention in HIV care: summary of sensitivity analyses

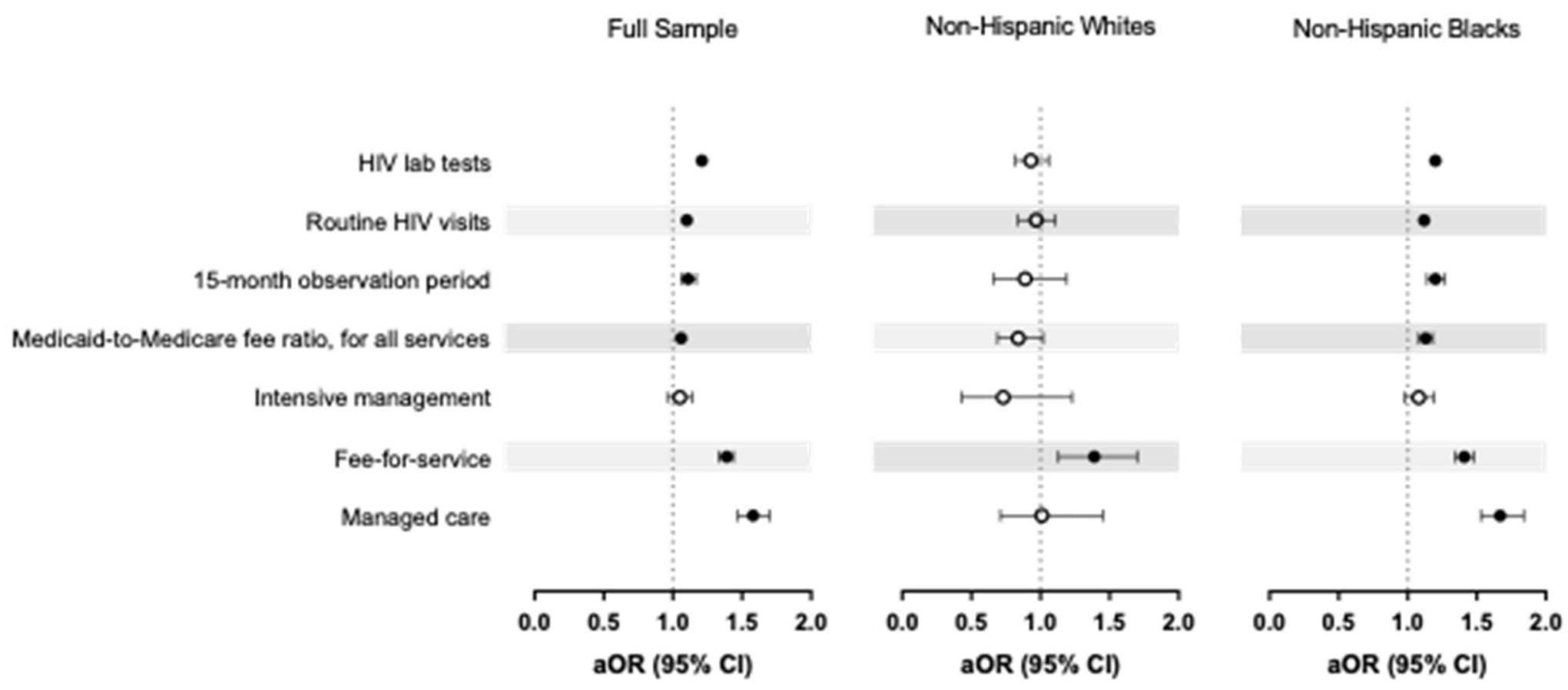

Abbreviations: $a O R=$ adjusted odds ratio; $C I=$ confidence interval

Legend: Reported are the adjusted odds of retention in HIV care with a 10-percentage point increase in the primary Medicaid-toMedicare fee ratio. Retention in care is defined as $\geq 2$ markers of care (physician visit, CD4, HIV RNA, or drug resistance tests, or antiretroviral prescriptions) within a calendar-year, with markers $\geq 90$ days apart. Regressions control for individual characteristics (age, sex, race/ethnicity, co-infections, comorbidities, and history of AIDS-defining illnesses), county characteristics (HIV prevalence, primary care physician supply, internal medicine specialist supply, number of hospital beds, urbanicity, percent with less than a high school education, percent unemployed, and median household income), and state- and time-fixed effects. HIV lab tests refers to $\geq 2$ CD4 or HIV RNA tests within a calendar-year, with markers $\geq 90$ days apart. Routine HIV visits refers to $\geq 2$ physician visit within a calendar-year, with markers $\geq 90$ days apart. 15 -month observation period refers to $\geq 2$ markers of care (physician visit, CD4, HIV RNA, or drug resistance tests, or antiretroviral prescriptions) within 15-month period (a calendar-year plus the first three months in the subsequent calendar-year), with markers $\geq 90$ days apart. The sample used for this sensitivity analysis is restricted to enrollees 
continuously enrolled in Medicaid for two years. Intensive management refers to a sub-sample of enrollees who have evidence of requiring intensive HIV management (due to pregnancy, HIV-related nephropathy, an AIDS-defining illness, or receipt of sulfamethoxazole/trimethoprim for pneumocystis jiroveci pneumonia) in a given calendar-year. Fee-for-service refers to a sub-sample of enrollees who have no evidence of managed care enrollment in a given calendar-year. Managed care refers to a sub-sample of enrolled in comprehensive care for at least 6 months in a given calendar-year. 
Table 1. Descriptive statistics for Medicaid enrollees living with HIV in 15 Southern states plus DC, 2008-2012

\begin{tabular}{|c|c|c|c|c|}
\hline Characteristic & Full sample & Non-Hispanic Whites & Non-Hispanic Blacks & $p$-value ${ }^{\mathrm{a}}$ \\
\hline Enrollees, $\mathrm{N}$ & 55,237 & 8,043 & 29,735 & \\
\hline Enrollee-years, Ny (\%) & $179,002(100.0)$ & $25,296(100.0)$ & $95,923(100.0)$ & \\
\hline Enrollee-years by year, Ny (\%) & & & & 0.380 \\
\hline 2009 & $33,969(19.0)$ & $4,755(18.8)$ & $18,176(19.0)$ & \\
\hline 2010 & $35,915(20.1)$ & $5,061(20.0)$ & $19,172(20.0)$ & \\
\hline Retained in care ${ }^{\mathrm{b}}, \mathrm{Ny}(\%)$ & $137,488(76.8)$ & $20,559(81.3)$ & $73,072(76.2)$ & $<0.001$ \\
\hline Medicaid-to-Medicare fee ratio, mean (SD) ${ }^{\mathrm{c}}$ & $0.70(0.14)$ & $0.68(0.15)$ & $0.69(0.15)$ & $<0.001$ \\
\hline \multicolumn{5}{|l|}{ Individual-level characteristics } \\
\hline$\overline{\text { Age group, } \mathrm{Ny}(\%)}$ & & & & $<0.001$ \\
\hline $55-64$ & $34,260(19.1)$ & $4,558(18.0)$ & $18,412(19.2)$ & \\
\hline Sex, Ny $(\%)$ & & & & $<0.001$ \\
\hline Female & $95,298(53.2)$ & $10,906(43.1)$ & $54,153(56.5)$ & \\
\hline Male & $83,704(46.8)$ & $14,390(56.9)$ & $41,770(43.6)$ & \\
\hline \multicolumn{5}{|l|}{ Race/Ethnicity, Ny (\%) } \\
\hline Non-Hispanic White & $25,296(14.1)$ & $25,296(100.0)$ & - & \\
\hline Non-Hispanic Black & $95,923(53.6)$ & - & $95,923(100.0)$ & \\
\hline Non-Hispanic Other ${ }^{\mathrm{d}}$ & $1,066(0.6)$ & - & - & \\
\hline Hispanic & $10,797(6.0)$ & - & - & \\
\hline Unknown/Missing & $45,920(25.7)$ & - & - & \\
\hline Number of coinfections ${ }^{\mathrm{e}}, \mathrm{Ny}(\%)$ & & & & $<0.001$ \\
\hline
\end{tabular}




\begin{tabular}{|c|c|c|c|c|}
\hline 1 or more & $20,635(11.6)$ & 3,201 (12.6) & $8,845(9.2)$ & \\
\hline Number of comorbidities ${ }^{\mathrm{f}}, \mathrm{Ny}(\%)$ & & & & $<0.001$ \\
\hline 0 & $124,077(69.3)$ & $17,490(69.1)$ & $67,336(70.2)$ & \\
\hline 1 or more & $54,925(22.1)$ & $7,806(30.9)$ & $28,587(30.1)$ & \\
\hline AIDS-defining illnesses ${ }^{\mathrm{g}}, \mathrm{Ny}(\%)$ & & & & 0.006 \\
\hline No AIDS-defining illnesses & $156,865(87.6)$ & $22,385(88.5)$ & $84,274(87.9)$ & \\
\hline AIDS-defining illnesses & $22,137(12.4)$ & $2,911(11.5)$ & $11,649(12.1)$ & \\
\hline Urbanicity $^{\mathrm{h}}, \mathrm{Ny}(\%)$ & & & & $<0.001$ \\
\hline Urban & $161,334(90.1)$ & $21,461(84.8)$ & $85,921(89.6$ & \\
\hline Rural & $17,668(9.9)$ & $3,835(15.2)$ & $10,002(10.4)$ & \\
\hline Enrolled in managed care at least 6 months ${ }^{\mathrm{i}}, \mathrm{Ny}(\%)$ & & & & $<0.001$ \\
\hline Yes & $133,356(74.5)$ & $18,394(72.7)$ & 66,507 (69.3) & \\
\hline No & $45646(25.5)$ & $6,902(27.3)$ & $29,416(30.7)$ & \\
\hline \multicolumn{5}{|l|}{ County-level characteristics } \\
\hline $\begin{array}{l}\text { HIV prevalence (diagnosed cases per 100,000 } \\
\text { population), mean (SD) }\end{array}$ & $902.2(726.9)$ & $487.3(405.8)$ & $885.0(687.2)$ & $<0.001$ \\
\hline $\begin{array}{l}\text { Number of primary care physicians per } 100,000 \\
\text { population, mean (SD) }\end{array}$ & $76.5(25.8)$ & $67.4(25.0)$ & $76.6(26.3)$ & $<0.001$ \\
\hline $\begin{array}{l}\text { Number of internal medicine specialists per 100,000 } \\
\text { population, mean (SD) }\end{array}$ & $124.4(85.2)$ & $81.5(53.0)$ & $117.8(77.4)$ & $<0.001$ \\
\hline Number of hospital beds, mean (SD) & $2970.9(2749.8)$ & $2253.9(2634.3)$ & $3057.9(2860.2)$ & $<0.001$ \\
\hline $\begin{array}{l}\text { Fraction of population with less than high school } \\
\text { diploma, mean (SD) }\end{array}$ & $0.10(0.03)$ & $0.10(0.03)$ & $0.10(0.03)$ & $<0.001$ \\
\hline $\begin{array}{l}\text { Fraction of population currently unemployed, mean } \\
\text { (SD) }\end{array}$ & $0.28(0.05)$ & $0.28(0.06)$ & $0.27(0.06)$ & $<0.001$ \\
\hline Median household income $(\$ 1,000)$, mean $(\mathrm{SD})$ & $49.6(12.0)$ & $48.4(9.8)$ & $50.4(11.7)$ & $<0.001$ \\
\hline
\end{tabular}

Abbreviations: $D C=$ District of Columbia; $N=$ number of enrollees; $N y=$ number of enrollee-years; $S D=$ standard deviation

${ }^{a}$ Chi-squared tests were used to test for differences in proportions between non-Hispanic White and non-Hispanic Black; $t$-tests were used for testing differences in means.

${ }^{\mathrm{b}}$ Defined as $\geq 2$ markers of care (physician visit; CD4, HIV RNA, or drug resistance tests; or antiretroviral prescriptions) within a calendar-year, with markers $\geq 90$ days apart. 
${ }^{\mathrm{c}}$ The mean Medicaid-to-Medicare fee ratio reported is at the enrollee-year level to account for the distribution of enrollees living with HIV by states.

d Defined as non-Hispanic Asians, American Indians, Alaskans, Hawaiians, or Pacific Islanders.

e Coinfections included hepatitis B and hepatitis C.

${ }^{f}$ Defined according to an adaption of the Charlson Comorbidity Index. ${ }^{32}$ AIDS is not included as a comorbidity and severity of comorbidities is not considered.

${ }^{\mathrm{g}}$ AIDS-defining illnesses were defined based on CDC guideline and the definition applied to a single calendar-year (see Supplement).

${ }^{\mathrm{h}}$ Individual-level urbanicity was based on the urbanicity of an enrollee's county of residence. Urban counties were counties in

federally designated metropolitan statistical areas with population $\geq 50,000$, while rural counties were in non-metropolitan statistical areas, adapted from the Urban-Rural Classification of the National Centers for Health Statistics. ${ }^{18}$

i The fraction of enrollees in managed care is estimated on an enrollee-year basis. 
Table 2. State-level Medicaid physician reimbursement and retention in HIV care: baseline analysis ${ }^{\mathrm{a}}$

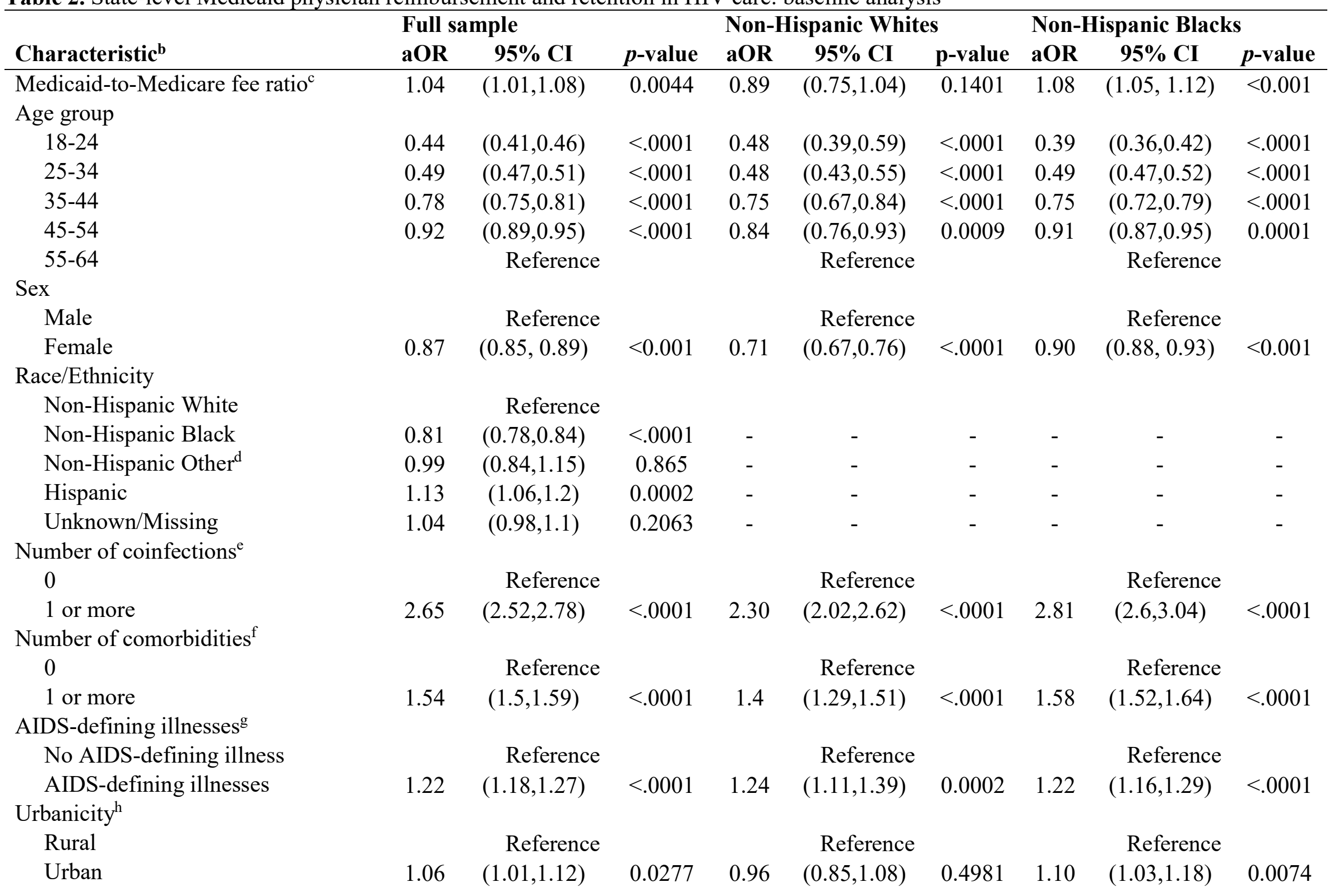




\section{Managed care ${ }^{\mathrm{i}}$}

Not enrolled in managed care

Reference

$1.82 \quad(1.77,1.87)$

$<.0001$

$2.73 \quad(2.53,2.94)$

$(2.53,2.94)$

$<0001$

Abbreviations: aOR $=$ adjusted odds ratio; $C I=$ confidence interval

${ }^{a}$ Report the adjusted odds of retention in HIV care with a 10-percentage point increase in the primary Medicaid-to-Medicare fee ratio. Retention in care is defined as $\geq 2$ markers of care (physician visit, CD4, HIV RNA, or drug resistance tests, or antiretroviral prescriptions) within a calendar-year, with markers $\geq 90$ days apart.

${ }^{\mathrm{b}}$ Regressions control for individual characteristics (age, sex, race/ethnicity, co-infections, comorbidities, and history of AIDS-defining illnesses), county characteristics (HIV prevalence, primary care physician supply, internal medicine specialist supply, number of hospital beds, urbanicity, percent with less than a high school education, percent unemployed, and median household income), and state- and time-fixed effects.

${ }^{\mathrm{c}}$ The adjusted odds of retention in HIV care are reported for a 10-percentage point increase in the Medicaid-to-Medicare fee ratio for primary care services.

${ }^{\mathrm{d}}$ Defined as non-Hispanic Asians, American Indians, Alaskans, Hawaiians, or Pacific Islanders.

${ }^{\mathrm{e}}$ Coinfections include hepatitis B and hepatitis C.

${ }^{\mathrm{f}}$ Defined according to an adaptation of the Charlson Comorbidity Index. ${ }^{32}$ AIDS is not included as a comorbidity and severity of comorbidities is not considered.

${ }^{g}$ AIDS-defining illnesses were defined based on CDC guidelines and applied to a single calendar-year (see Supplement).

${ }^{h}$ Individual-level urbanicity was based on the urbanicity of an enrollee's county of residence. Urban counties were counties in federally designated metropolitan statistical areas with population $\geq 50,000$, while rural counties were in non-metropolitan statistical areas, adapted from the Urban-Rural Classification of the National Centers for Health Statistics. ${ }^{18}$

${ }^{\mathrm{i}}$ Enrolled in managed care is defined as enrollment in managed care for at least 6 months within a given calendar-year. 